\title{
Quatro princípios ópticos para a construção de glifos: estabilidade, obstrução, densidade e demarcação
}

\author{
Four principles for glyph construction: stability, obstruction, density and demarcation
}

Sérgio Luciano da Silva, Sérgio Antônio Silva

Design de faces, ilusão de óptica, tipografia

\begin{abstract}
O presente artigo tem por objetivo apresentar algumas particularidades da percepção visual humana, assim como possíveis estratégias de construção de glifos que burlem os efeitos ópticos indesejáveis, no design de faces de tipos. A análise se apóia, principalmente, nos estudos realizados por Peter Karow e Karen Cheng sobre ilusão de óptica aplicada à tipografia e nas interpretações que Walter Tracy e Victor Gaultney oferecem sobre os conceitos de legibilidade e leiturabilidade. A partir disso, uma exposição textual e ilustrada de alguns fenômenos ópticos conhecidos serve de base para o que consideramos a contribuição deste trabalho para o design de faces de tipo: a elaboração de quatro princípios (estabilidade, obstrução, densidade e demarcação) e a organização de conceitos, com a finalidade de propor critérios de correção e ajuste na forma dos glifos.
\end{abstract}

Typeface design, optical illusion, typography

The purpose of this paper is to present some particularities of the human sight perception as well as possible glyph construction strategies that can get rid of unwanted optical effects in typeface design. This analysis is based mainly on the studies developed by Peter Karow and Karen Cheng about optical illusion applied to typography and on the interpretation Walter Tracy and Victor Gaultney offer for the concepts of legibility and readability. From there on, the presentation of some known optical phenomena, in text and illustrations, is used as the basis for what we consider as the contribution of the present work to typeface design: the elaboration of four principles (stability, obstruction, density, and demarcation) and the organization of concepts, both aiming at proposing correction criteria and adjustments in the form of the glyphs.

\section{Introdução}

Algo que se aprende nos estudos de desenho geométrico é contar sempre com as ferramentas e os instrumentos de medida para a confecção de trabalhos confiáveis. O mundo contemporâneo, ainda em grande medida mecanicista, se baseia neste princípio, que por sua vez se funda na matemática. Quando não seguimos suas regras, nas chamadas ciências exatas e áreas correlatas, comprometemos seriamente nossos projetos. Se, buscamos a precisão matemática de uma representação geométrica, devemos usar a régua, o esquadro e o compasso, em sua forma física ou computadorizada. Entretanto, uma figura desenhada seguindo estes critérios matemáticos, apesar de ter um alto grau de precisão, não será vista assim pela maior parte dos seres humanos. Isso se deve a características específicas de nossa percepção visual. Desta maneira, se procuramos a imagem perfeita, dentro dos parâmetros de nossa visão, devemos esquecer a tradição matemática fundada por Platão e difundida pela metodologia de Descartes e confiar em nossos olhos. Este preceito, válido para o desenho figurativo em duas dimensões, estende-se também para o universo da criação tipográfica.

\section{Ilusão de óptica e compensação}

Peter Karow em seu livro Digital formats for typefaces ${ }^{1}$ apresenta uma série de testes ópticos compostos apenas por quadrados, círculos e triângulos (Karow, 1987: 25). Esses testes foram feitos primeiramente em 130 pessoas pela URW (empresa fundada em Hamburgo em 1971 e da

\footnotetext{
${ }^{1}$ O termo typeface (face de tipo) é muitas vezes confundido com o termo fonte tipográfica. Uma face de tipo é uma coleção de letras, sinais diacríticos, números, pontuação e símbolos desenhados para terem uma forma e estilo comuns. Uma fonte tipográfica é uma estrutura que descreve uma face de tipo, seja fisicamente, em blocos de liga de metal e filme fotográfico ou digitalmente, em código de computador.
}

InfoDesign | Revista Brasileira de Design da Informação / Brazilian Journal Information Design São Paulo | v. 7 | n. 1 [2010], p. 11 - 21 | ISSN 1808-5377 
qual Karow era sócio). O propósito inicial desses exames foi estabelecer parâmetros seguros para a correção óptica que a URW deveria incluir no desenho de suas faces de tipo. Posteriormente, Karow fez a transcrição dos testes para o livro, para que cada leitor pudesse realizá-los e tirar suas próprias conclusões. O que está por trás dessa experiência é algo que caracteriza a maneira como a maioria dos seres humanos vê formas em duas dimensões:

1. Um quadrado parece ser quadrado quando sua altura é $1 \%$ maior que sua largura.

2. Um círculo parece ter o mesmo tamanho de um quadrado quando seu diâmetro é $3 \%$ maior que a altura do quadrado.

3. Um Triângulo deve ter $3 \%$ a mais de altura e $5 \%$ a mais de largura respectivamente à altura e ao lado de um quadrado para parecer tão alto ou tão largo quanto este quadrado.

Os dados apresentados na lista anterior devem ser considerados valores médios, uma vez que cada pessoa percebe de forma um pouco distinta cada uma dessas figuras. De qualquer maneira, isso coloca-nos em alerta para o fato de que em design de faces nem sempre há correspondência entre o que medimos e o que vemos. A sequência de figuras a seguir (figuras 1 a 6 ) confirma isso.

Na figura 1, em A, temos um quadrado e um círculo da mesma altura. Para a maioria das pessoas o círculo parece menor que o quadrado. Em B, o mesmo quadrado e o mesmo círculo são duplicados. Com o auxílio de duas linhas, comprova-se visualmente que a altura de ambos é idêntica. Em C, o quadrado e o círculo parecem ter a mesma altura (também para a maioria das pessoas), mas quando repetidos em $\mathrm{D}$, novamente com o auxílio das linhas, percebemos que o círculo é maior que o quadrado.

Figura 1: Círculos ao lado de quadrados

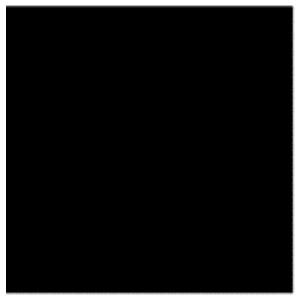

A
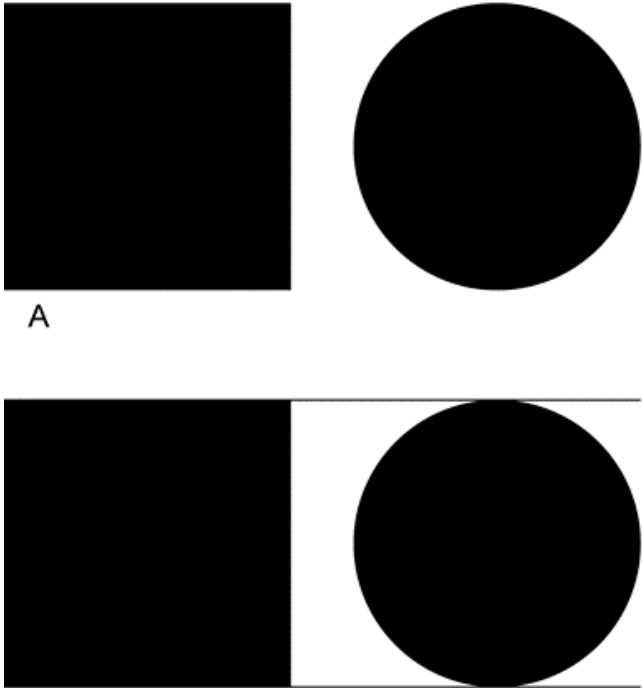

(

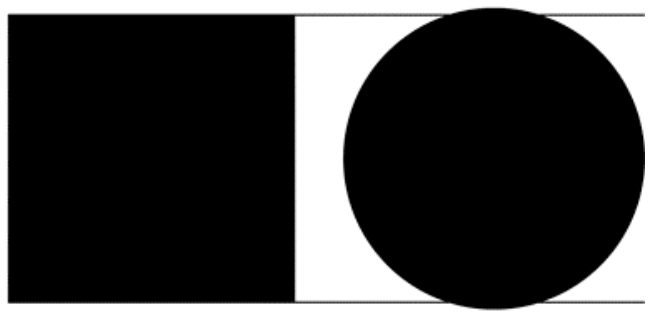

D

Na figura 2, outro caso de ilusão de óptica significativa, quando dois círculos de mesmo tamanho são colocados um sobre o outro. Em A, os dois círculos tem o mesmo tamanho. Entretanto, quase todas as pessoas terão a impressão de que o círculo de baixo é menor. Já nos dois círculos em $B$, apesar de parecerem do mesmo tamanho, o de baixo é um pouco maior. Em $C$ (réplica de A) e $D$ (réplica de B), com o auxilio de três linhas equidistantes, podemos comprovar a ilusão.

Figura 2: Círculos sobre círculos

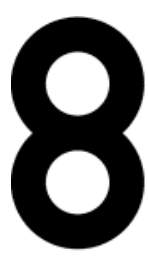

A

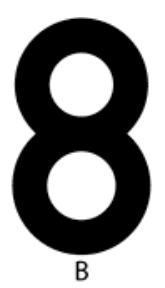

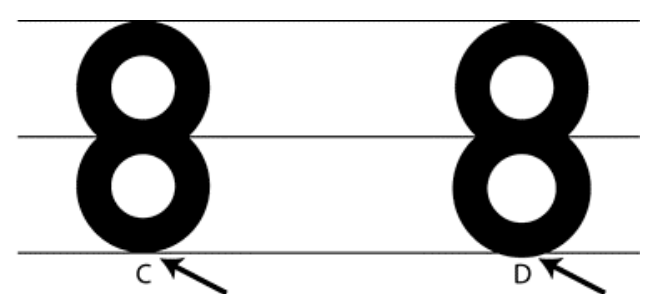


Na figura 3, em A, uma barra diagonal atravessa um retângulo. A impressão que temos é de que a barra que toca o lado esquerdo do retângulo sai defasada para cima do lado direito. Em $B$, a barra atravessa o retângulo sem nenhuma defasagem ou quebra. No entanto, em $C$ (réplica de A), com o tom cinza aplicado apenas ao retângulo, comprova-se que a barra não está realmente defasada. Em D (réplica de B) podemos ver o truque de construção usado para "convencer" nossos olhos, ou melhor, nosso cérebro, de que B é a imagem correta. Um componente que pode potencializar os efeitos desta ilusão de óptica é o contraste entre grosso e fino nas figuras que se cruzam. Quanto maior for este contraste, mais os efeitos da ilusão se fazem sentir.

Figura 3: Diagonais que se cruzam
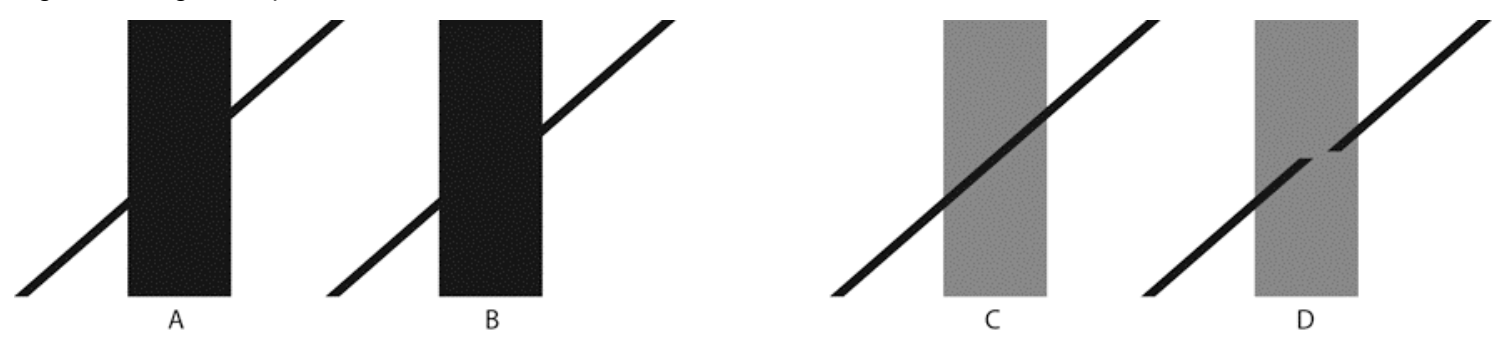

Na figura 4, em A, podemos ver os detalhes de construção de uma forma constituída de círculos e retas. Em B, aparece a mesma figura concluída em que ocorre uma ilusão de óptica: as partes verticais parecem flexionar-se para dentro, o que levou tal aparente deformação a receber o nome de efeito osso. Para reduzir esse efeito é preciso suavizar a transição entre as linhas retas e curvas, conforme foi feito em $\mathrm{C}$. A linha pontilhada, no detalhe ampliado em $\mathrm{E}$, identifica a curvatura original e o contorno em cinza da nova curva suavizada. Em D, aparece a figura final com a correção na curvatura e a ilusão de óptica minimizada. Conforme Peter Karow, as transições mais efetivas, entre retas e curvas, ocorrem quando se faz uso de uma clotóide, um tipo de espiral que é comumente utilizada na construção do traçado de rodovias (Karow, 1987: 23).

Figura 4: O efeito osso

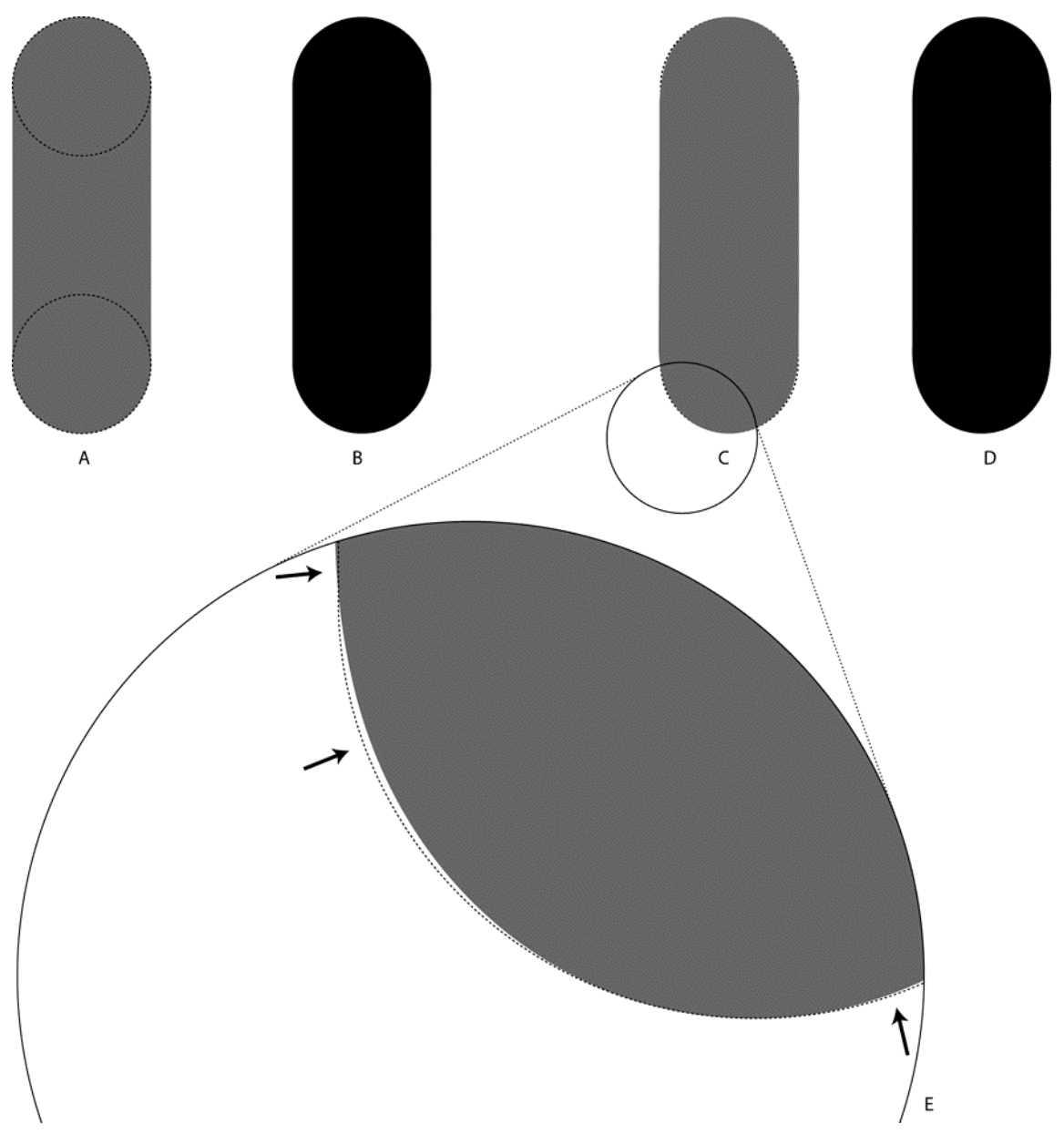


$\mathrm{Na}$ figura 5 pode-se notar como barras verticais tendem a parecer mais finas que horizontais. Em A, temos os detalhes de construção de uma figura constituída por dois retângulos assemelhandose à letra $T$. A largura do retângulo na vertical é igual à altura do retângulo na horizontal, o que pode ser comprovado pelo quadrado pontilhado formado na área de interseção de ambos. Em $B$, a mesma figura está concluída e a barra horizontal aparenta ser um pouco mais grossa que a vertical. Para eliminar esse efeito, devemos fazer os retângulos horizontais mais finos que os verticais, conforme C e D.

Figura 5: Verticais conectadas a horizontais
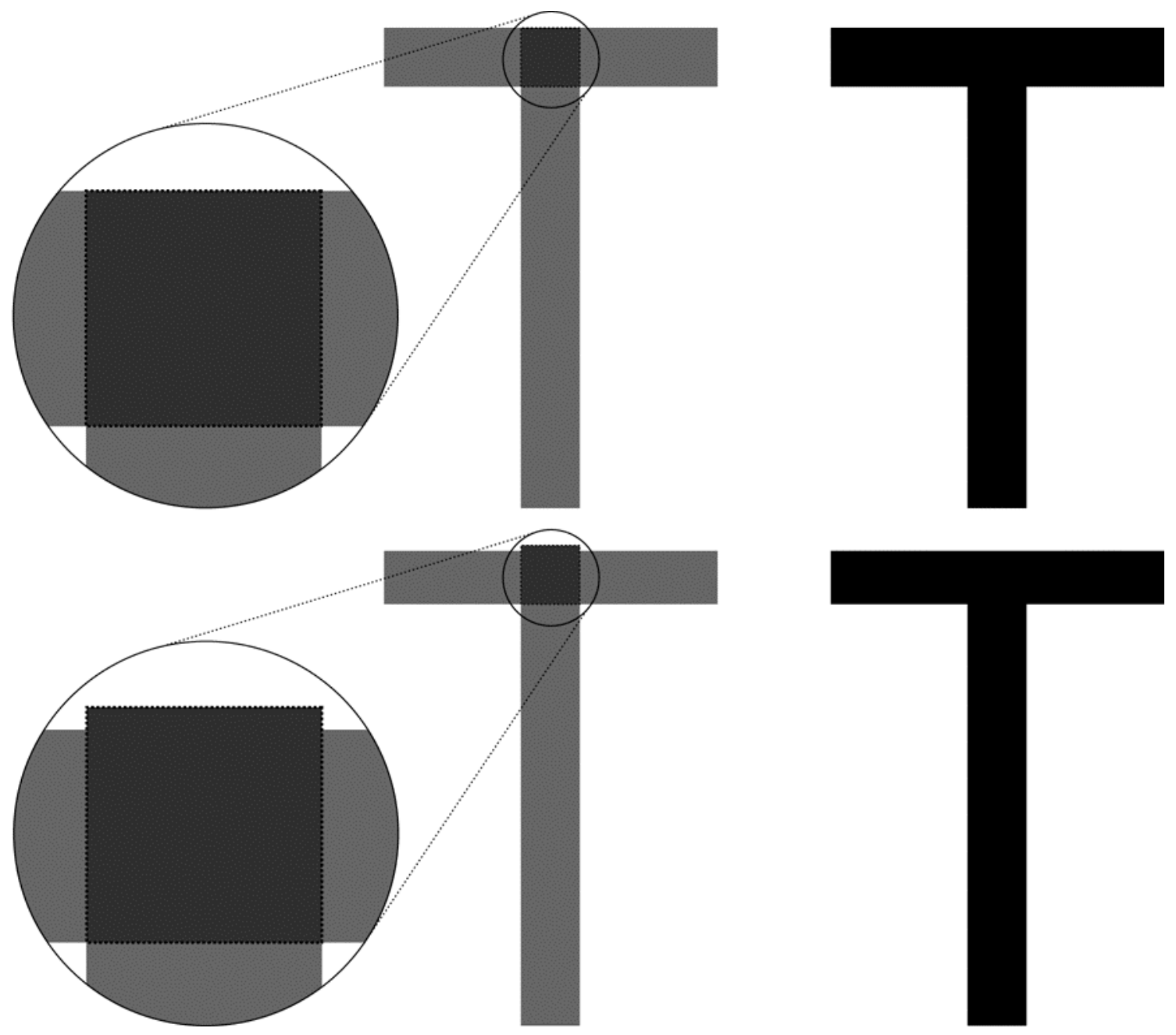

Na figura 6, no desenho de uma forma curva como a que é mostrada em A, a largura no eixo vertical deve ser maior que a largura no eixo horizontal, para que o traçado pareça homogêneo. Formas verticais parecem ser mais largas do que as circulares de mesma espessura, portanto, devem ser mais finas, para manterem a uniformidade com as circulares, conforme a comparação das medidas entre A e B. Além disso, as formas circulares devem ultrapassar a altura das verticais e diagonais para parecerem do mesmo tamanho destas. Por último, as formas em diagonais parecem ser mais largas que as verticais de mesma espessura, devendo também ser ajustadas, conforme a comparação entre B e C. 
Figura 6: Outras curvas, retas e diagonais (medidas expressas em pontos tipográficos)

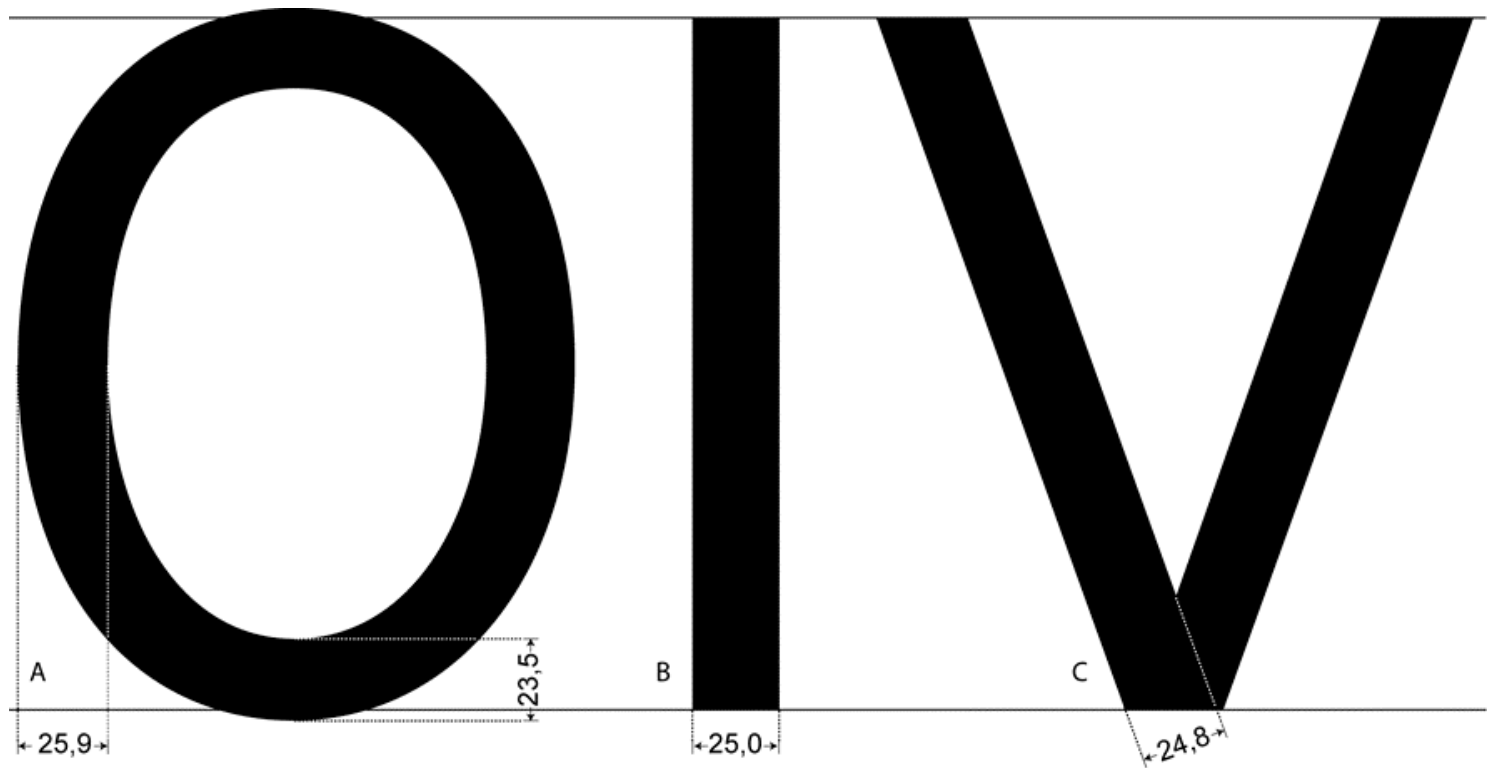

A análise das ilusões de óptica que mais afetam a visão humana, no ato da leitura, tem como objetivo oferecer ao designer de faces recursos, para que o mesmo saiba compensar tais efeitos, dominando técnicas para escapar dessas armadilhas visuais. Obviamente, autores especializados em tipografia têm abordado este tema, seja na forma de artigos, como Mark Jamra (1993) e Victor Gaultney (2001), ou com informações distribuídas no conteúdo de obras mais extensas, como Peter Karow (1987) e Karen Cheng (2006). No entanto, para o designer (no exercício da criação tipográfica) é fundamental ter sempre em mente os padrões mais comuns de ilusão de óptica, para proceder às correções necessárias com segurança. Ora, quando sabemos o que procurar, tornase mais fácil encontrar. Assim, tendo por base os fenômenos ópticos expostos até aqui, buscamos extrair deles alguns conceitos e estabelecer o que consideramos a contribuição principal deste trabalho para o desenvolvimento do design de faces, isto é, quatro princípios heurísticos ${ }^{2}$. Tais princípios ajudam a identificar e corrigir, opticamente, estruturas formais em desenhos, orientando o traçado de partes potencialmente problemáticas dos glifos. Nós os denominamos princípios da estabilidade, da obstrução, da densidade e da demarcação, sendo os mesmos analisados a seguir. Como derivam dos efeitos ópticos já expostos, suas proposições também estão sujeitas às variações da percepção visual de cada um de nós, seres humanos. Desta maneira, devem ser entendidos antes como referenciais de construção e não como regras absolutas.

\section{Estabilidade}

Observando a sequência de letras da figura 7 e atentando somente para os aspectos visuais, um dos pontos que pode ser ressaltado diz respeito a como cada glifo se posiciona verticalmente. Imaginemos que cada letra é um objeto físico sujeito à força da gravidade e que é atraído para acomodar-se sobre um plano horizontal. As letras de formas retangulares como o $D, E$ e $H$ se equilibram naturalmente. Já as letras como o / e Y não têm uma área inferior ampla para manterem-se tão facilmente de pé. No caso de letras como o $\mathrm{V}, O, C$ e $S$, o equilíbrio torna-se mais comprometido ainda. O princípio da estabilidade dispõe que, quanto mais equilibrado visualmente for o desenho de um glifo, maior será a sua legibilidade.

\footnotetext{
${ }^{2}$ Heurísticos, no sentido de hipóteses de trabalho sem pretensão de aplicação universal. Isto porque, em sistemas de escritas muito distintos dos alfabetos (como os silabários Hiragana e Katakana) esses princípios devem ser reelaborados.
} 
Figura 7: O princípio de estabilidade

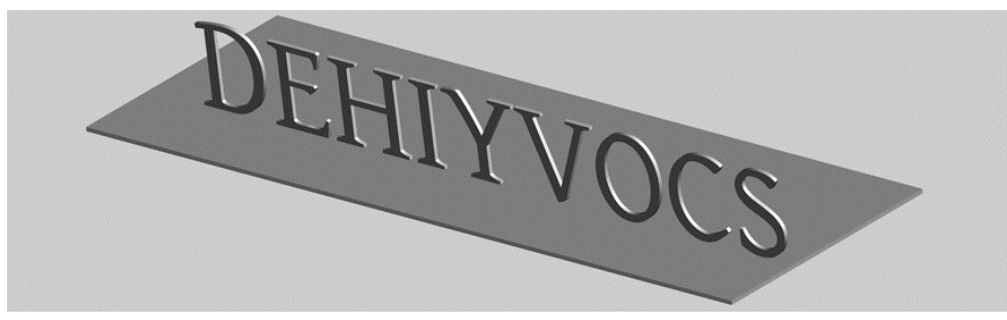

Os artifícios utilizados para garantir a aplicação desse princípio são inúmeros, mas a figura 8 apresenta alguns exemplos. Nos dois primeiros itens (letras $E$ e $B$ ), os mecanismos de ajustes são mais fáceis de se detectar. Para aumentar a estabilidade da letra $E$, dois recursos diferentes são aplicados. O primeiro é fazer a altura do braço central desta letra acima do centro geométrico ${ }^{3}$ do retângulo que a delimita. Como consequência, a área interna inferior desta letra torna-se um pouco maior, aumentando com isso a sensação visual de equilíbrio da mesma. O segundo é desenhar o braço e a serifa inferior do $E$ mais compridos que os outros dois, reforçando a estabilidade da base. A letra $B$ tem como fundamento de estabilidade um bojo maior em sua parte inferior. No caso do $S$, o procedimento foi dar maior destaque para a área inferior da letra, com a mesma intenção de ampliar a sustentação da base. No entanto, nessa letra esta característica é mais sutil e somente fica evidente quando inserimos os círculos cinza nos miolos das duas curvas e o círculo inferior se revela maior que o superior.

Sempre que possível, é importante aumentar a estabilidade de uma letra, mesmo no caso de um $H$, normalmente muito estável. O recurso aqui foi elevar sua barra horizontal acima do centro geométrico da letra.

Figura 8: Exemplos relacionados ao princípio de estabilidade

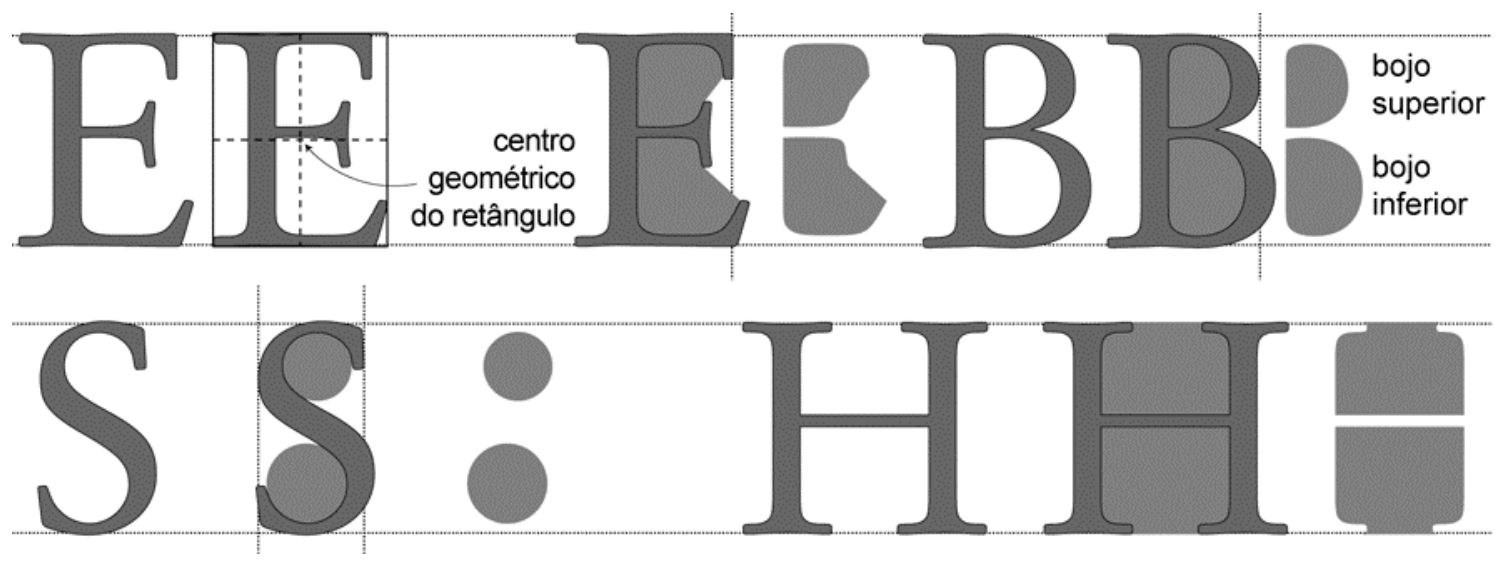

\section{Obstrução}

O princípio da obstrução estabelece que as diversas partes de um glifo devem se relacionar entre si de forma a não criarem congestionamentos nas suas junções ou gargalos nos espaços internos. $\mathrm{Na}$ figura 9, o $E, K$ e $W$ tiveram algumas serifas internas reduzidas para não criar gargalos. Tanto o $p$ serifado quanto o $p$ sem serifa têm soluções diferentes para o mesmo problema de congestionamento nas junções. No primeiro a resposta foi estreitar o bojo na junção e no segundo foi inclinar a parte de cima da haste.

\footnotetext{
${ }^{3}$ Centro geométrico é o ponto em que as coordenadas são as médias das coordenadas dos pontos que formam uma figura geométrica.
} 
Figura 9: Exemplos relacionados ao princípio de obstrução

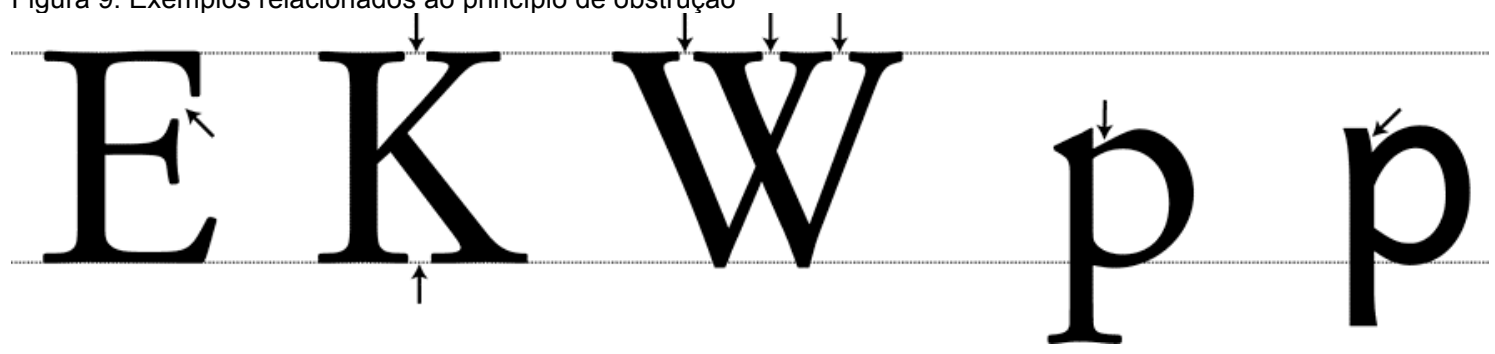

\section{Densidade}

Cada glifo tem uma estrutura física que preenche uma área específica com cor, para moldar sua forma. O princípio da densidade estabelece que glifos de formas similares devem manter equivalência aproximada entre suas áreas, para garantir uniformidade dos seus pesos visuais. $\mathrm{Na}$ figura 10 temos a sequência de letras $C, G, C$, e e (desenhadas em linhas de contorno), que baseiam sua construção na letra $O$ (desenhada em cinza). As aberturas destas letras tendem a torná-las mais leves em relação à letra $O$, que é fechada. Para compensar esta "perda de massa" o contorno nestas letras é adensado nas partes indicadas pelas setas.

Figura 10: Exemplos relacionados ao princípio de densidade

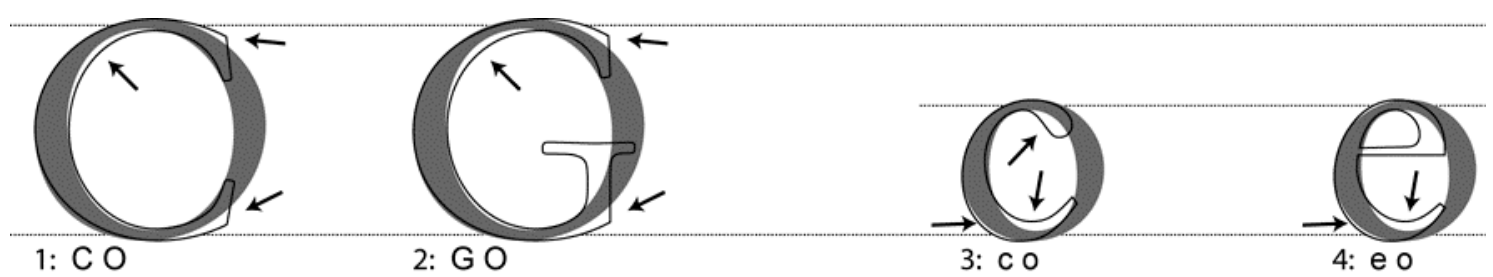

\section{Demarcação}

Uma das tarefas mais complexas de serem executadas, e ao mesmo tempo essenciais em um projeto de criação tipográfica, diz respeito ao espaçamento das letras. O princípio da demarcação (diretamente associado às questões de espaço) estabelece que as partes dos glifos que se destacam do próprio corpo devem ter suas distâncias reguladas, para não se chocarem com outros glifos. Letras potencialmente candidatas para a aplicação deste princípio contêm elementos que se afastam lateralmente do seu corpo como as pernas do $K$ e do $R$, o rabo do $Q$ e a parte externa da serifa do pescoço do $G$ (itens 1 a 4 da figura 11). Este afastamento pode ser problemático também em letras com ascendentes, como $b$ e $d$, ou com descendentes, como $p$ e $q$, quando estas partes são construídas muito alongadas. É necessário pensar ao mesmo tempo a forma dos glifos e a sua interação com todos os demais, seja na distribuição horizontal (construção de uma linha de texto), seja na distribuição vertical (construção de diversas linhas, umas sobre as outras).

Figura 11: Exemplos relacionados ao princípio de demarcação

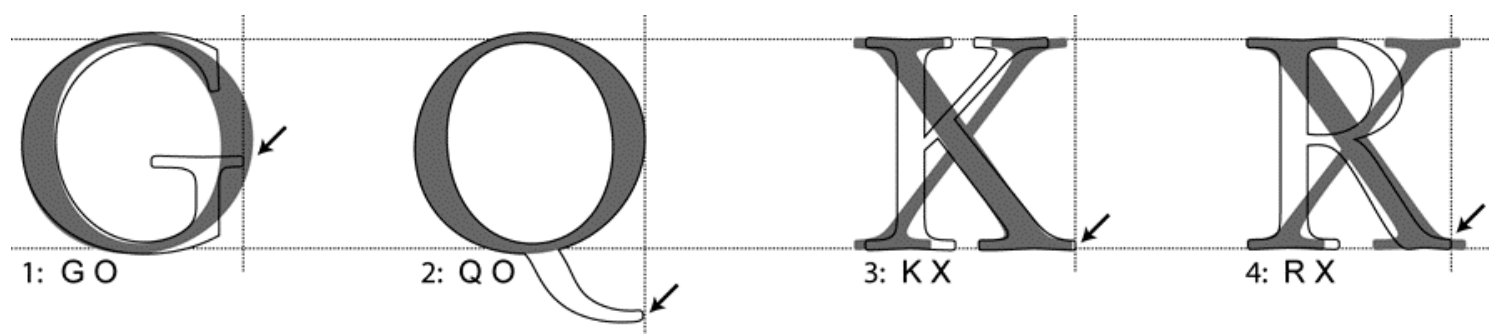

Para concluir sobre os quatro conceitos anteriores, é digno de atenção como diversos termos foram concebidos, ao longo da história da tipografia, de maneira antropomórfica. Por exemplo, em relação às partes das letras, temos ombros, braços, pernas, pescoços, orelhas, olhos e barrigas. Procurando manter essa tradição "anatômica", podemos afirmar que os dois primeiros princípios (o de estabilidade e o de obstrução) são endógenos, atuando especificamente no interior de cada glifo. E os outros dois (o de densidade e o de demarcação) são exógenos, operando sempre na relação entre dois ou mais glifos. Além disso, às vezes, um ou mais princípios atuam associados. 
Por exemplo, o aumento de densidade da parte de baixo da letra $C$ (item 1 da figura 10) serve tanto ao princípio de densidade quanto ao princípio de estabilidade.

\section{Legibilidade e leiturabilidade}

Em sua vertente exógena, quando a investigação volta-se para a análise específica dos efeitos visuais que advêm da relação mútua entre os glifos, mais particularmente entre as letras, a questão passa a ser objeto de estudo de diversos campos além do nosso, como o da psicologia cognitiva, da pedagogia e da alfabetização. Devido às limitações de espaço, faremos somente algumas delimitações, para aclarar pontos fundamentais sobre o tema geral da legibilidade.

Em tipografia, como em todas as áreas do conhecimento humano, muitos conceitos necessitam de definição bem específica para tornarem claros seus significados e sentidos, por vezes exclusivos. E se determinada palavra não se mostra capaz de expressar um conceito, nada mais justo do que criarmos uma nova para fazê-lo. Os gregos foram os precursores desse tipo de procedimento, quando há mais de 2.500 anos apropriavam-se das palavras de uso comum ou inventavam outras para criar o vocabulário específico da então emergente filosofia. O caso presente é digno de distinção, pois está baseado não em uma, mas em duas palavras inglesas: legibility e readability. Legibility tem como seu correspondente em português a palavra legibilidade, mas o mesmo não ocorre com readability. Não consideramos adequado traduzir apenas uma delas, mantendo outra em sua língua de origem, já que as mesmas tratam de um tema comum e, neste caso, aparecem juntas. Assim, traduziremos readability por leiturabilidade, um neologismo por vezes utilizado em textos de língua portuguesa.

Quando um leitor percorre um texto no processo de leitura, além de visualizar toda uma massa de signos, ele os decifra, extraindo deles significado. Nesse processo, conforme afirma Walter Tracy (2003: 31), legibilidade refere-se à clareza com que o leitor identifica as letras individuais e leiturabilidade diz respeito ao maior ou menor conforto visual que o mesmo tem durante o tempo em que lê. Em resumo, legibilidade está associada à percepção visual, enquanto leiturabilidade diz respeito à compreensão. É claro que se pode argumentar que a distinção é desnecessária e que esses dois conceitos poderiam ser incorporados como apenas dois aspectos de uma mesma concepção mais ampla de legibilidade. Apesar de não fazer uso deste argumento, Victor Gaultney, por exemplo, em artigo sobre legibilidade e economia de espaço (Gaultney, 2001: 1), desconsidera tal distinção, o que também fazemos aqui, visando à inteligibilidade do texto.

\section{Legibilidade de letras similares}

Uma importante característica associada à legibilidade diz respeito aos elementos que distinguem letras com estruturas similares como o $h$ e o $b$ ou o $h$ e o $n$. A figura 12 mostra, em A, as letras $h$ e $b$ produzidas na fonte SIL DoulosL Italic e, em B, as mesmas letras na URW Garamond $N^{\circ} 8$ Italic. A estrutura do terminal da letra $h$ na DoulosL (indicada com o círculo) direciona-se para fora do conjunto da letra, sendo um elemento a mais a distingui-la de uma letra similar como o $b$. Já com a Garamond $\mathrm{N}^{\circ} 8$, o terminal inferior é voltado para dentro, o que pode levar o leitor a confundi-la com a letra $b$, em corpos de texto de tamanhos reduzidos. Em C, as letras $h$ e $n$ na fonte URW Gothic $L$ têm uma altura-x bastante expressiva, o que faz com que a ascendente do $h$ seja relativamente curta e torna a forma de ambas muito parecidas em tamanhos reduzidos. $E m D$, as mesmas letras $h$ e $n$ aparecem na fonte SIL Andika DesRev D, que tem uma altura-x menor em relação às ascendentes, o que favorece a distinção entre as duas letras. Estes exemplos evidenciam uma particularidade da legibilidade. Em tamanhos reduzidos é que a identificação das formas das letras se torna crítica, portanto, é importante estar atento a isso no momento das escolhas, principalmente quando o objetivo é o desenvolvimento de faces para aplicação em longos blocos de texto corrido, de dimensões menores, em alfabetização, ou para uso de portadores de deficiência visual. 
Figura 12: Elementos que distinguem letras com estruturas similares

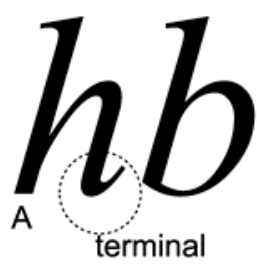

terminal

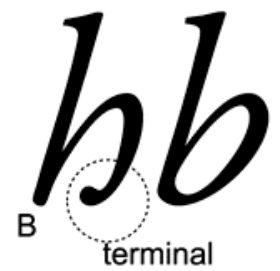

terminal
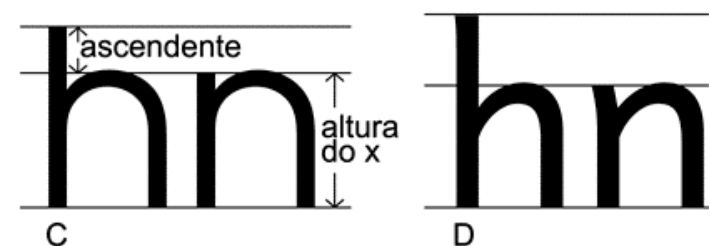

A compreensão de um texto escrito se deve em parte pela identificação que fazemos das diferentes formas dos topos das letras (Felici, 2003: 43). Isto porque, no alfabeto latino, as partes superiores das letras tem mais variações que as partes inferiores. Conforme pode ser visto na figura 13, a mesma frase que aparece completa em C torna-se muito difícil de decifrar em A, mas é relativamente fácil de ler em $B$. Portanto, é nessa região que os esforços em prol da legibilidade devem ser concentrados no momento do desenho das letras do alfabeto latino. Por outro lado, não se pode ignorar que cada sistema de escrita tem características próprias e às vezes singulares. $\mathrm{A}$ escrita hebraica, por exemplo, ao contrário da latina, tem mais variações nas partes inferiores de suas letras, exigindo do designer um cuidado e apuro maior, justamente nessas áreas.

Figura 13: A importância das partes superiores das letras no alfabeto latino

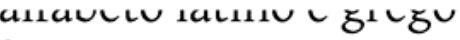

A

alfahoto latinn o rrorn

B alfabeto latino e grego

\section{Organizando os conceitos para estabelecer os critérios}

Existem, claro, outros fenômenos de natureza óptica que influenciam a percepção visual que temos das formas em duas dimensões, e, consequentemente, também das letras. De qualquer modo, a partir do que foi analisado aqui é possível organizar os conceitos e propor alguns procedimentos no trabalho de criação tipográfica:

1. O que é matematicamente ou geometricamente correto nem sempre é percebido por nós humanos (através dos olhos) como correto. Um dos pontos que mais pode prejudicar a criação de faces de tipo bem proporcionadas é o fato de nossa percepção visual, de um modo geral, exagerar as dimensões horizontais em relação às verticais. É essencial estar sempre atento a esse e aos demais fenômenos ópticos já vistos.

2. As ilusões de óptica dos tipos vistos anteriormente costumam atuar de maneira pulsante. O efeito aparece num instante e desaparece no seguinte, para logo depois reaparecer. Estar ciente desta característica auxilia na observação das formas.

3. A conjunção de determinadas formas, em determinadas posições, pode produzir os diversos tipos de efeitos indesejados. Daí, como visto anteriormente, a necessidade de ter sempre em mente os padrões mais comuns de ilusão de óptica, para proceder às correções necessárias com segurança. Entretanto, se em algum momento houver dúvida, a solução pode ser usar os conceitos e uma régua. Por exemplo, ao desconfiar que uma barra horizontal, que se conecta com uma vertical, parece mais grossa, basta medi-las. Se a horizontal for da mesma espessura da vertical, a ilusão está confirmada e podemos seguramente proceder ao ajuste.

4. Além de ter os conceitos em mente, é importante treinar o olhar, pois todo ajuste ou compensação depende também dos olhos e da experiência do designer. Sendo em boa parte subjetiva, a compensação irá variar também de face para face. Cada face de tipo exigirá um procedimento próprio, único.

5. Tão importante quanto detectar um fenômeno óptico é ter consciência de que ele ocorre para uma parte apreciável dos seres humanos. Além disso, mesmo fazendo parte do grupo que não percebe uma ilusão, é fundamental agir para eliminá-la (ou pelo menos 
minimizá-la), uma vez que seus efeitos podem ser maiores ou menores, dependendo do grau de sensibilidade de cada observador.

6. Não existem valores preestabelecidos, nem números mágicos. A experimentação e os testes é que permitirão fixar cada valor de compensação. Um bom auxílio é fazer impressões dos desenhos em tamanhos variados, desde os bastante reduzidos até os muito grandes. E após uma primeira avaliação deixá-los de lado por algum tempo, enquanto se descansa o olhar. Estes procedimentos podem parecer pouco rigorosos do ponto de vista geométrico, mas não podemos nos esquecer de que estamos lidando com a percepção visual humana e não com matemática pura. Em parte por causa disso e da consequente carga de subjetividade que comporta a tipografia é que este campo técnico também está atrelado à cultura e à arte.

7. Fazer uso da subjetividade não significa de modo algum ser impreciso. No interior de um determinado projeto de criação tipográfica, depois de estabelecido um valor de ajuste para um fenômeno óptico específico, deve-se ter o cuidado de mantê-lo igual para todas as formas que necessitem deste ajuste. Tomemos como exemplo o trabalho de redução do efeito osso. O valor de ajuste de transição entre linhas retas e curvas, deve ser fixado como padrão para todo o projeto.

\section{Considerações finais}

O sétimo item da lista anterior poderia fornecer argumentos a um matemático platônico ou cartesiano de que, na verdade, o discurso subjacente aqui não está tão afastado assim da tradição geometrizante do mundo contemporâneo. Na verdade, não está. Ora, se a intenção deste texto é estabelecer princípios e propor critérios, de alguma maneira estamos rendendo homenagem a Platão e a Descartes. E todos nós sabemos que um projeto tipográfico consistente não é viável sem o poderoso auxílio das mais diversas ferramentas matemáticas, estejam elas na mente do designer, em suas mãos, ou dentro do computador. No entanto, não podemos nem devemos nos esquecer de que tipografia, tanto na criação quanto na fruição, envolve também a aparência e o olhar. Indo além do objetivo atual, do ponto de vista da criação, este olhar não pode prescindir da história, da cultura e muito menos da caligrafia. Mas este é um tema para outra ocasião.

\section{Referências}

CHENG, Karen. Designing Type. New Haven: Yale University Press, 2006. 232 páginas.

FELICI, James. The Complete Manual of Typography: a guide to setting perfect type. Berkeley: Peachpit Press, 2003. 362 páginas.

GAULTNEY, J. Victor. Balancing typeface legibility and economy: practical techniques for the type designer. 2001. 14 páginas. Disponível em:

<http://scripts.sil.org/cms/scripts/render_download.php?site_id=nrsi\&format=file\&media_id=Bala nLegEcon.pdf\&filename=BalanLegEcon.pdf $>$ Acesso em: $2 \overline{8}$ ago. 2010.

JAMRA, Mark. Some elements of proportion and optical image support in a typeface. 1993. 6 páginas. Disponível em:

<http://www.typeculture.com/academic_resource/articles_essays/pdfs/tc_article_6.pdf> Acesso em: 28 ago. 2010.

KAROW, Peter. Digital formats for typefaces. Hamburg: URW Verlag, 1987. 400 páginas.

ROSSI FILHO, Sérgio. Graphos: glossário de termos técnicos em comunicação gráfica. São Paulo: Editorial Cone Sul, 2001. 738 páginas.

TRACY, Walter. Letters of credit: a view of type design. Boston: David R. Godine Publisher, 2003. 224 páginas.

\section{Sobre os autores}

Sérgio Antônio Silva é Doutor em Letras: Estudos Literários pela Universidade Federal de Minas Gerais (UFMG); professor da Escola de Design da Universidade do Estado de Minas Gerais (UEMG), atuando na Graduação em Design Gráfico e no Mestrado em Design, com disciplinas, 
orientações e pesquisas ligadas à semiótica e às teorias da escrita. Leciona ainda no curso de Letras do Centro Universitário de Sete Lagoas. É autor de A hora da estrela de Clarice.

<sergio.antonio74@hotmail.com>

Sérgio Luciano da Silva é mestrando em Design pela Universidade do Estado de Minas Gerais, ED/UEMG, com o projeto "Faces e fontes em multiescrita: fundamentos e critérios de design tipográfico". Suas pesquisas atuais envolvem estudos em filosofia, grego antigo, latim, hebraico, caligrafia medieval e renascentista. Sócio da Adaequatio Estúdio de Criação, atua principalmente com sinalização indicativa e interpretativa de cidades históricas, exposições de parques ambientais, projetos gráficos de livros e criação tipográfica.

<sergiolucianosilva@gmail.com> 